\title{
The Generation of Water in the Tobacco Oven Volatile Test*
}

\author{
by M. C. Bourlas, D. F. Magin, R. A. Kornfeld and T. S. Laszlo \\ Philip Morris U.S.A., Research Center, Richmond, Virginia, U.S.A.
}

\section{INTRODUCTION}

The economic and technological importance of water in tobacco processing and cigarette manufacturing has required the close control of tobacco moisture content (1-3). The water content of tobacco affects the smooth operation of machinery, it is a controlling parameter in expansion processes, it is essential in minimizing breakage in all blending, conveying and making operations, and certainly the moisture content is an important factor in mass balance and accountability studies. Since proper control is essential throughout all processing steps, it is important that the water content be measured at all stages of processing (4).

\section{A. Approaches to Tobacco Moisture Determination}

Two fundamentally different approaches are being used for the determination of tobacco moisture content: [1] in situ procedures which include electrical and radiation methods and [2] separation methods such as desiccant, solvent extraction - distillation, Karl Fischer, and various heating techniques. The array of choices seems large in number yet, because of the complex nature of tobacco, measuring water in tobacco quantitatively remains a problem. Many of the more direct approaches are affected by tobacco parameters other than moisture content, for example electrolyte content and chemical composition. The indirect approach of separating water from tobacco requires knowledge of the solvent properties of the extracting media and of how well a particular solvent system removes water from the tobacco matrix. Desiccant methods, using intense drying agents, are unsuitable not only because the desiccant attracts volatile organic substances, but also because the length of time per determination is excessive.

The thermal drying technique (5) [oven volatiles (OV)] is the most widely used method for the determination of water in tobacco. The procedure has many advantages (simplicity, precision, reliability), yet the OV method has

\footnotetext{
* Presented, in part, at the Coresta Technology and Smoke Study Groups joint meeting held in Munich, Germany, in 1977 and at the 32nd Tobacco Chemists' Research Conference, 1978, Montreal, Canada.

Received: 15th April 1979 - accepted: 2nd May 1980.
}

met with criticism for quite some time. The basis for this criticism is that under the conditions of the procedure, not only may tobacco volatiles other than water be liberated, but decomposition of some organic substances is likely to occur with the generation of water. The percent of volatiles measured would thus be higher than the true water content.

\section{B. Data Supporting the Decomposition Mechanism}

Thermogravimetric analysis (TGA) of uncased Bright tobacco tends to support this criticism (Figure 1). While greater than $90 \%$ of the weight loss found at three hours occurs in the first fifteen minutes, the sample continues to lose weight under isothermal conditions $\left(100^{\circ} \mathrm{C}\right)$ even after the specified three-hour limit. In an OV determination, therefore, the nearly dry tobacco is heated at $100^{\circ} \mathrm{C}$ for the major portion of the three-hour test period.

One conclusion, drawn from a critical evaluation of other moisture determination methods, is that there exists a significant difference between results obtained by the oven drying technique and non-thermal procedures. The data in Table 1 show an average difference of $2.4 \%$ obtained by the OV and Karl Fischer methods for cased tobaccos while a $1.2 \%$ difference is observed for uncased

Figure 1. Thermogravimetric analysis of Bright uncased tobacco:

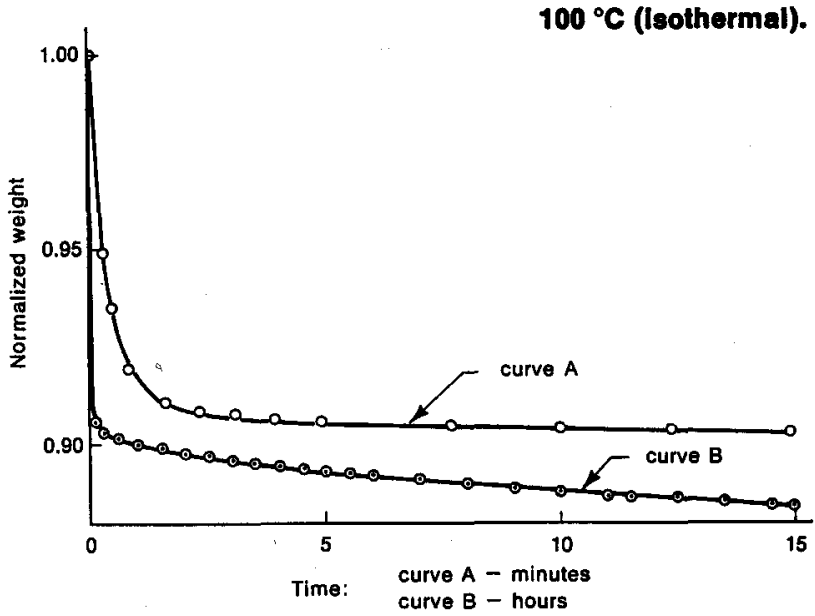


Table 1. Oven volatlles and Karl Flscher molsture determinatlons *.

\begin{tabular}{ll|c|c}
\hline Sample & Oven volatiles (\%) & Karl Fischer (\%) \\
\hline Virginia & B & 10.4 & 7.6 \\
Burley & A & 15.9 & 13.8 \\
Burley & B & 10.7 & 9.0 \\
Blend & A & 19.4 & 17.0 \\
Blend & B & 12.6 & 10.1 \\
Blend & C & 11.3 & 10.0 \\
Bright & A & 13.1 & 12.1 \\
Bright & B & 12.6 & 11.2 \\
Bright & C & 11.3 & 10.2 \\
\hline
\end{tabular}

- First five samples are cased, last four are uncased.

tobacco. The Karl Fischer procedure utilizes methanol as the extracting solvent and the assumption is made that this solvent is capable of removing all water present in the tobacco regardless of the bonding (chemical, physicalchemical, mechanical) responsible for the retention of water. The validity of this assumption is not critical in order to address the decomposition hypothesis pertaining to the thermal technique since in comparing $O V$ test results with other moisture methods, the conclusions are the same - the OV test results are consistently higher.

In order to further explore the observed difference, the following experimental program was carried out. Subsequent to equilibrating Bright, uncased tobacco at $75^{\circ} \mathrm{F}$ and $60 \%$ relative humidity, both Karl Fischer and OV tests were performed on the filler. The oven-dried tobacco was re-equilibrated under the same conditions for an additional week and the same analyses were performed. The procedure was then repeated for a second time. The results are shown in Table 2. The Karl Fischer moisture of equilibrated tobacco is consistently lower $(\approx 1.3-1.5 \%)$ than the percent oven volatiles after the original equilibration. The difference, however, is smaller when the tobacco is heat treated and re-equilibrated and it becomes of questionable significance (range overlap) if heat treated and re-equilibrated for the second time. The comparison of the OV and Karl Fischer results before and after oven treatment suggests that the decomposition of the tobacco constituents is diminished after the tobacco is thermally treated.
These comparative data support the proposition that a portion of the water liberated during an oven volatile test is derived from the degradation of organic substances in the tobacco. The test of the validity of this proposition was the subject of the following study.

\section{ANALYTICAL METHODOLOGY}

\section{A. Experimental Design}

Two forms of isotopically labelled water are readily available $-{ }^{2} \mathrm{H}_{2} \mathrm{O}$ and $\mathrm{H}_{2}{ }^{18} \mathrm{O}$. Because of the ease and rate of deuterium exchange (6-8) with labile hydrogen (alcohols, acids, amines, etc.), ${ }^{2} \mathrm{H}_{2} \mathrm{O}$ was judged not to be suitable for these investigations. In contrast, oxygen isotopic exchange reactions (9) occur less readily and require, in most cases, acidic or basic conditions and higher temperatures than do deuterium exchange processes. Thus, the use of $\mathrm{H}_{2}{ }^{18} \mathrm{O}$ provides a means for differentiating between water $\left(\mathrm{H}_{2}{ }^{16} \mathrm{O}\right)$ that may be generated by degradation during the oven volatile test and the water $\left(\mathrm{H}_{2}{ }^{18} \mathrm{O}\right)$ added for equilibrating the tobacco. The two forms of water were easily distinguishable by mass spectrometry. In the present study, a CEC* 21-104 mass spectrometer was used at $10 \mu \mathrm{A}$ electron emission current and $2400 \mathrm{eV}$ ion accelerating voltage. The ionizing electron energy was lowered from $70 \mathrm{eV}$ until the $\mathrm{M}_{\mathrm{H}_{2} \mathrm{O}^{-2}}$ ion intensity was less than $0.05 \%$ of the $\mathrm{M}_{\mathrm{H}_{2} 0}$ ion intensity.

The highly enriched $\mathrm{H}_{2}{ }^{18} \mathrm{O}(>98 \%)$ used to equilibrate the tobacco filler will maintain its isotopic purity if, during the thermolysis process, no water is liberated or no loss of $\mathrm{H}_{2}{ }^{18} \mathrm{O}$ occurs from tobacco constituents. The percent molar isotope ratio (MIR) may be defined by equation 1

$$
\begin{aligned}
& \text { Molar isotope ratio }(\%)= \\
& =\frac{\frac{\mathrm{H}_{2}{ }^{18} \mathrm{O}(\mathrm{g})}{20}}{\frac{\mathrm{H}_{2}{ }^{16} \mathrm{O}(\mathrm{g})}{18}+\frac{\mathrm{H}_{2}^{18} \mathrm{O}(\mathrm{g})}{20}} \times 100
\end{aligned}
$$

and may be taken as a direct measure of the overall perturbation in the initial balance of $\mathrm{H}_{2}{ }^{18} \mathrm{O}$ and $\mathrm{H}_{2}{ }^{18} \mathrm{O}$.

* Consolidated Electronics Corporation

\begin{tabular}{|c|c|c|c|c|c|c|c|c|c|c|c|c|}
\hline \multirow[b]{2}{*}{ Analysis } & \multicolumn{4}{|c|}{$\begin{array}{l}\text { Original equilibration } \\
\text { at one week }\end{array}$} & \multicolumn{4}{|c|}{$\begin{array}{l}\text { 1st re-equilibration } \\
\text { at the end of two weeks }\end{array}$} & \multicolumn{4}{|c|}{$\begin{array}{l}\text { 2nd re-equilibration } \\
\text { at the end of three weeks }\end{array}$} \\
\hline & $\mathbf{n}$ & $\bar{x}$ & $\operatorname{RSD}(2 \sigma)^{\star}$ & Range & $n$ & $\bar{x}$ & $\operatorname{RSD}(2 \sigma)$ & Range & $\mathbf{n}$ & $\bar{x}$ & $\operatorname{RSD}(2 \sigma)$ & Range \\
\hline Oven volatiles (\%) & 24 & 11.5 & 1.7 & $11.3-11.7$ & 12 & 10.7 & 1.1 & $10.6-10.8$ & 6 & 9.8 & 1.1 & $9.7-10.0$ \\
\hline \multirow[t]{3}{*}{$\begin{array}{l}\text { Karl Fischer moisture } \\
\qquad\left(\% \mathrm{H}_{2} \mathrm{O}\right)\end{array}$} & 6 & 10.0 & 2.1 & $9.8-10.2$ & 6 & 9.8 & 2.6 & $9.5-10.1$ & 5 & 9.4 & 4.5 & $8.9-9.8$ \\
\hline & & & & & \multicolumn{4}{|c|}{$\begin{array}{c}\text { Original equilibration } \\
\text { at } 2 \text { weeks }\end{array}$} & \multicolumn{4}{|c|}{$\begin{array}{l}\text { Original equilibration } \\
\text { at } 3 \text { weeks }\end{array}$} \\
\hline & & & & & $n$ & $\bar{x}$ & $\operatorname{RSD}(2 \sigma)$ & Range & $\mathbf{n}$ & $\bar{x}$ & $\operatorname{RSD}(2 \sigma)$ & Range \\
\hline \multirow{2}{*}{\multicolumn{5}{|c|}{$\begin{array}{l}\text { Repeat: oven volatiles (\%) } \\
\text { Repeat: Karl Fischer moisture }\left(\% \mathrm{H}_{2} \mathrm{O}\right)\end{array}$}} & 6 & 11.6 & 1.3 & $11.4-11.7$ & 6 & 11.1 & 1.9 & $10.9-11.4$ \\
\hline & & & & & 6 & 10.3 & 2.3 & $10.0-10.5$ & 6 & 9.8 & 6.6 & $9.2-10.4$ \\
\hline
\end{tabular}

Table 2. Molsture determinatlon of equilibrated tobacco before and after oven drying.

- RSD (2o) = Relative standard deviation at the $2 \sigma$ level, i. e. the $95 \%$ confidence limits. 
Figure 2. Flow dlagram of experimental procedure.

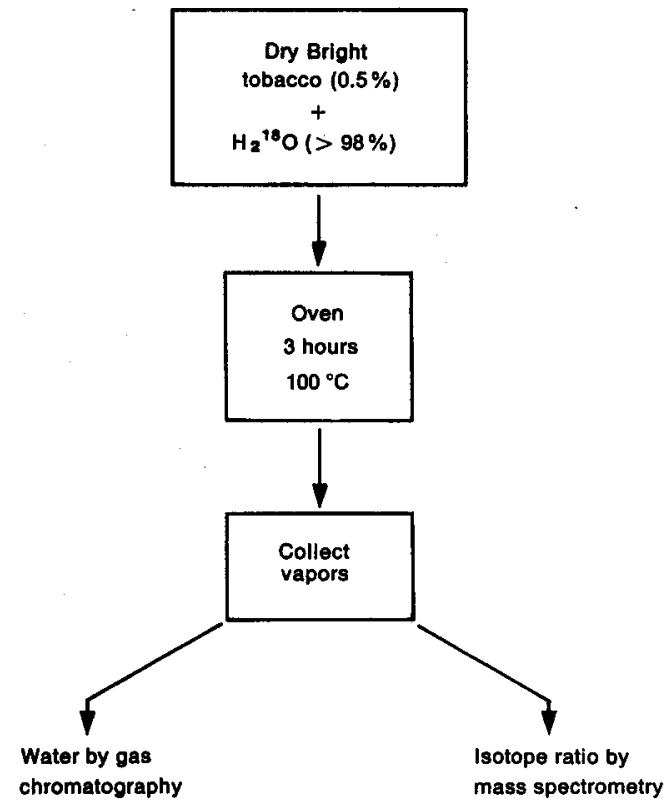

\section{B. Experimental Procedure}

The block diagram shown in Figure 2 illustrates the overall procedure. All experimental steps from the initial drying and equilibrating of the tobacco to the final analysis of the collected vapors, were conducted in such a manner as to prevent exposure to the surrounding atmosphere, thus minimizing the exchange of isotopically labelled water with atmospheric water. A sufficiently large "dry box" was utilized and filled with all necessary equipment for the experiment. Dry nitrogen, obtained from the headspace of a liquid nitrogen tank, was allowed to pass through the "dry box" for a period of three weeks. Bright uncased cut tobacco was dried inside the "dry box" over molecular sieve (Union Carbide 3A) by first placing the tobacco in a desiccator containing the drying agent for a period of two weeks and then transferring it to a second desiccator containing fresh molecular sieve for two additional weeks. Karl Fischer moisture determination performed on the dried tobacco yielded $0.5 \%$ as its water content. Following the drying cycle, the tobacco was equilibrated for 48 hours with $\mathrm{H}_{2}{ }^{18} \mathrm{O}$ by adding a specific amount (by weight) to a known weight of dry tobacco (approximately $100 \%$ by weight). Subsequent to the equilibration step, the tobacco was subjected to $\mathrm{OV}$ conditions ( 3 hours, $100^{\circ} \mathrm{C}$ ) and the tobacco volatiles collected in an evacuated flask (Figure 3 ). The collected water was quantitatively determined by gas chromatography while the isotopic enrichment was determined by mass spectrometry.
Figure 3. Experimental apparatus designed for collectine oven volatiles.

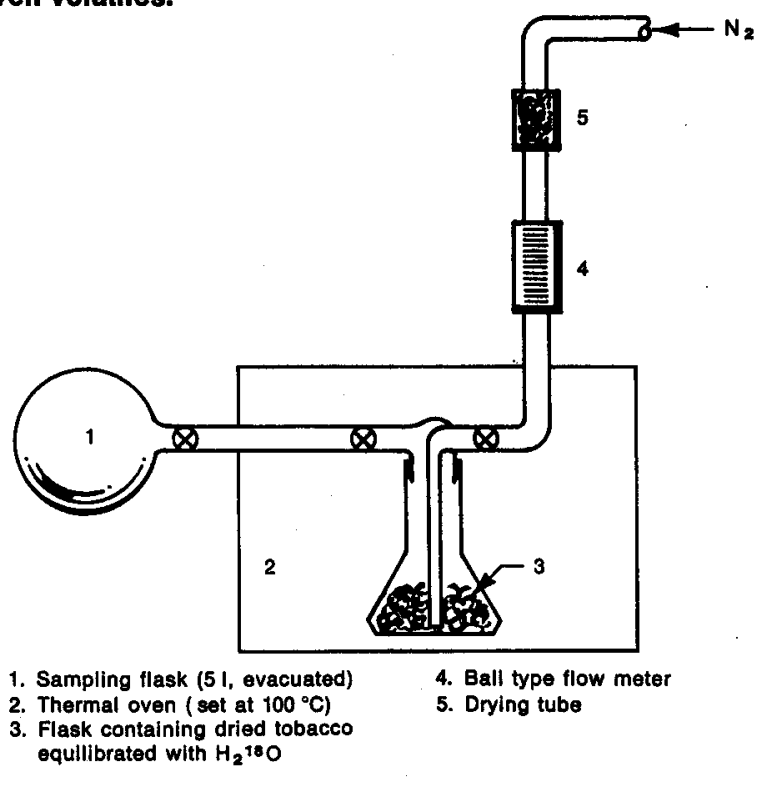

\section{RESULTS AND DISCUSSION}

It has been proposed that a portion of the water liberated during an oven volatiles test is derived from the thermal degradation of organic substances in the tobacco. This decomposition hypothesis which is proposed in order to explain discrepancies between thermal and non-thermal techniques has been tested and results of each individual

Table 4. Determination of tobacco moisture following first oven cycle *t.

\begin{tabular}{lr}
\hline Water collected & $+5.1 \pm 2.3$ \\
(increase in \%) & $92.4 \pm 1.2$ \\
Initial molar isotope ratio (\%) & $74.2 \pm 5.1$ \\
Experimental molar isotope ratio (\%) & $87.6 \pm 2.9$ \\
Molar isotope ratio (\%) expected &
\end{tabular}

- Oven volatile conditions: $100^{\circ} \mathrm{C}$ for 3 hours.

+ Average of nine determinations.

experiment are presented in Table 3. A summary of these data is presented in Table 4. In all cases the amount of water collected during the three-hour $100^{\circ} \mathrm{C}$ treatment of tobacco exceeds the weight of water added for the equilibration by an average value of approximately five percent. These results support the proposition that certain tobacco substances are degraded in such a manner as to yield water as one of the by-products. Furthermore, the theoretical molar isotope ratio (MIR) shown in Table 4,

Table 3. Results for first oven cycle *.

\begin{tabular}{|c|c|c|c|c|c|c|c|c|c|c|}
\hline I. & Weight of $\mathrm{H}_{2} \mathrm{O}^{10} \mathrm{O}(\mathrm{mg})$ initially present & 829 & 990 & 738 & 838 & 802 & 415 & 382 & 409 & 598 \\
\hline 11. & Weight of $\mathrm{H}_{2}{ }^{18} \mathrm{O}(\mathrm{mg})$ initially present & 55 & 44 & 59 & 68 & 58 & 35 & 26 & 35 & 46 \\
\hline III. & Weight of water (mg) collected & 948 & 1054 & 839 & 940 & 914 & 490 & 417 & 463 & 687 \\
\hline IV. & Initial molar isotope ratio (\%) & 93 & 95 & 92 & 92 & 93 & 91 & 93 & 91 & 92 \\
\hline V. & Experimental molar isotope ratio (\%) & 80 & 82 & 70 & 77 & 78 & 70 & 68 & 71 & 72 \\
\hline VI. & Molar isotope ratio (\%) expected from $\mathrm{H}_{2}{ }^{16} \mathrm{O}$ gained & 86 & 93 & 87 & 88 & 87 & 83 & 91 & 87 & 86 \\
\hline
\end{tabular}

" Oven test conditions: $100^{\circ} \mathrm{C}$ for 3 hours. 
Table 5. Determination of tobacco molsture following second oven drying.

\begin{tabular}{|c|c|c|c|}
\hline & \multicolumn{3}{|c|}{ Sample No." } \\
\hline & 1 & 2 & 3 \\
\hline 1. Weight of $\mathrm{H}_{2}{ }^{18} \mathrm{O}$ added $+(\mathrm{mg})$ & 460 & 550 & 620 \\
\hline II. Weight of water collected $(\mathrm{mg})$ & 466 & 549 & 619 \\
\hline $\begin{array}{l}\text { III. Molar isotope ratio (\%) } \\
\text { of water added }\end{array}$ & 99 & 99 & 99 \\
\hline $\begin{array}{l}\text { IV. Molar isotope ratio (\%) } \\
\text { of water collected }\end{array}$ & 93 & 88 & 83 \\
\hline $\begin{array}{l}\text { Equilibration time: } \\
\text { sample No. 1: } 48 \text { hours } \\
\text { sample No. 2: } 72 \text { hours } \\
\text { sample No. 3: } 96 \text { hours }\end{array}$ & & & \\
\hline
\end{tabular}

$92 \%$, is significantly reduced during the thermal treatment of the tobacco. This ca. $18 \%$ reduction may be caused by either [1] an increase in the amount of $\mathrm{H}_{\mathbf{2}}{ }^{10} \mathrm{O}$ (liberated during heating cycle) and/or [2] a decrease in the amount of $\mathrm{H}_{2}{ }^{18} \mathrm{O}$ present in final mixture. The fact that more water was collected than was originally added to the tobacco eliminates the latter mechanism as a sole cause. If no loss of $\mathrm{H}_{2}{ }^{18} \mathrm{O}$ occurred and the experimental MIR reduction arises from an increase in $\mathrm{H}_{2}{ }^{18} \mathrm{O}$ only, then the MIR expected would be noticeably higher (ca. $88 \%$ ) than what was observed (see Table 4). Therefore, the former method of reducing the molar isotope ratio may also be excluded as the sole cause. The most plausible explanation for observing a decrease in the MIR appears to be a combination of $\mathrm{H}_{2}{ }^{1{ }^{1} \mathrm{O}}$ generation via both decomposition and oxygen-18 exchange with tobacco components. The variation in the molar isotope ratios prevents the definitive quantitative separation of exchange and decomposition mechanisms; however, qualitatively the trend in the data clearly indicates that both processes are in operation.

It is not unlikely under the conditions used that oxygen exchange reactions take place to some extent (9-13). Following equilibration with $\mathrm{H}_{2}{ }^{18} \mathrm{O}$ and treatment through the oven, oxygen-18 is incorporated in those substances whose oxygens are labile enough to undergo oxygen transfer. In accordance with the DTA data, the rate of decomposition should be significantly reduced after thermal treatment. A re-equilibration of tobacco having gone through the oven once should give a measure of the extent of 0-18 exchange. The results of such an experiment are shown in Table 5. The amount of water collected during the second thermal treatment of the tobacco is the same as was initially added indicating that the water generation by decomposition has ceased. This is supported by the observation that the difference between the calculated and experimental molar isotope ratios was significantly reduced. Furthermore, since $\mathrm{H}_{2}{ }^{18} \mathrm{O}$ is added to the dried tobacco, which has been oven treated, on the same day and the collected water analyzed on three consecutive days, the reduction in the MIR is indicative of a time dependency of the oxygen exchange process taking place during the equilibrium period. Subjecting the dried tobacco to a third cycle results in similar differences between theoretical and experimental MIR while the isotopic exchange ratio remains time-dependent.

The complexity of tobacco precludes a total mechanistic interpretation of the interaction between the equilibrium moisture and tobacco. The equilibration and subsequent decomposition experiments as well as the oxygen-18 exchange data support the hypothesis that a portion of the equilibrium water is capable of exchanging with a variety of tobacco components. These tobacco components may be of two types: [1] labile compounds which subsequently decompose at typical OV test temperatures to yield water and [2] thermally stable oxygen-containing compounds. Prolonged heat treatment reduces the former class of substances but the latter remains intact with partial oxygen-18 incorporation. The isotope exchange occurring in the first cycle continued during the re-equilibration for the second cycle but was reduced due to chemical changes which took place during the first equilibration-thermolysis step.

The reversible addition of water to carbonyl compounds has been well documented and verified by a number of chemical and instrumental techniques (14). The ease with which hydration reactions occur suggests that part of the incorporation may be due to this mechanism. To test this assumption, tobacco which was dried with molecular sieve, equilibrated with $\mathrm{H}_{2}{ }^{18} \mathrm{O}$, and oven treated was extracted with $\mathrm{H}_{2}{ }^{16} \mathrm{O}(0.15 \mathrm{~g} / \mathrm{ml})$ and allowed to stand at ambient conditions for five days. Mass spectrometric determination of the oxygen-18 enrichment of the water showed a $0.12 \%$ increase over natural abundance. This

Table 6. Quantitative determination and ${ }^{18} \mathrm{O}$-enrichment of acetlc acid.

\begin{tabular}{|c|c|c|c|}
\hline $\begin{array}{l}\text { Tobacco } \\
\text { sample* }\end{array}$ & Treatment & $\begin{array}{l}\text { Acetic acid ** } \\
(\mu g / g)\end{array}$ & $\begin{array}{c}{ }^{18} \mathrm{O} \text { - acetic acid } \\
(\mu \mathrm{g} / \mathrm{g})\end{array}$ \\
\hline A & Molecular sieve dried (no oven treatment) & 77 & N.D. ${ }^{++}$ \\
\hline B & Sample A: re-equilibrated with $\mathrm{H}_{2}{ }^{18} \mathrm{O}$ and oven treated & 22 & N.D. \\
\hline $\mathrm{C}$ & Sample A: re-equilibrated with $\mathrm{H}_{2}{ }^{18} \mathrm{O}$ & 648 & 330 \\
\hline D & Sample B: re-equilibrated with $\mathrm{H}_{2}{ }^{16} \mathrm{O}$ & 356 & 121 \\
\hline
\end{tabular}

* All samples are Bright uncased tobacco.

* Quantitative determination by gas chromatography (GC): Varian-2400 GC with a $5^{\prime} \times 1 / 8^{\prime \prime}$ nickel column packed with $5 \% \mathrm{FFAP}+0.5 \% \mathrm{H}, \mathrm{PO}, 80-100$ mesh Chromosorb-W (acid washed).

+ Determined with a Finnigan-3000 (electron energy $70 \mathrm{eV}$ ).

++ N.D. $=$ not detectable. 
Table 7. Oxygen-18 Incorporation In reducing sugars * In Bright tobacco.

\begin{tabular}{|c|c|c|c|}
\hline $\begin{array}{c}\text { Tobacco } \\
\text { sample }\end{array}$ & Treatment & $\begin{array}{l}\text { Glucose } \theta^{+} / \\
\text {glucose-18 } \mathrm{O}^{\text {* * }}\end{array}$ & $\begin{array}{l}\text { Fructose } e^{+} / \\
\text {fructose-18 }{ }^{1 *}\end{array}$ \\
\hline A & Molecular sieve dried (no oven treatment) & $4.8 \% /$ N.D. ${ }^{++}$ & $8.0 \%$ / N.D. ${ }^{++}$ \\
\hline B & $\mathrm{H}_{2}{ }^{14} \mathrm{O}$-equilibrated oven volatiles & $4.4 \% / 55 \%$ & $7.2 \% / 74 \%$ \\
\hline $\mathrm{C}$ & Sample B: equilibrated with $\mathrm{H}_{2}{ }^{10} \mathrm{O}$ oven volatiles & $3.6 \% / 65 \%$ & $6.0 \% / 75 \%$ \\
\hline
\end{tabular}

- No significant oxygen-18 incorporation was observed in sucrose.

+ Reported as \% by welght. Quantitative determination by GC: Varian-2700 GC with a 6 ' $1 / 8^{\prime \prime}$ nickel column packed with $3 \%$ oV-17 on Supelcoport (100-120 mesh).

** Represents minimum amount (\%) of reducing sugar incorporation oxygen-18. Determined with a Finnigan-3000 (electron energy 70 eV).

++ N.D. = not detected.

increase accounted for $66 \%$ of the oxygen-18 (from $\mathrm{H}_{2}{ }^{18} \mathrm{O}$ ) loss due to the exchange mechanism, vide supra. The vast number of oxygen-containing organic compounds in tobacco capable of undergoing oxygen transfer prevents a total mass balance from being established. Accounting for $66 \%$ of the oxygen-18 loss suggests that incorporation has indeed taken place.

To confirm this dynamic interaction between equilibrium moisture and the tobacco matrix, however, required establishing the presence of incorporated oxygen-18 in specific tobacco components. Acetic acid $(\approx 0.1 \%$ by weight in equilibrated Bright tobacco) was determined both quantitatively and for oxygen-18 enrichment (Table 6). The drying of tobacco either using molecular sieve (sample A) or the oven method (sample B) reduces the acetic acid content (the latter procedure to a greater degree) while re-equilibrating previously dried tobacco regenerates acetic acid. The source of acetic acid is not clear at this time, but the isotopic enrichment [34\% (sample D)] is consistent with the proposal that the tobacco/water system is interactive. The mass of oxygen-18 due to exchange with acetic acid is insignificant, however, since the total measured incorporation accounts for only $\approx 0.6 \%$ of the total $\mathrm{H}_{2}{ }^{18} \mathrm{O}$ lost.

A more plausible exchange process that may occur involves $\mathrm{H}_{2}{ }^{18 \mathrm{O}}$ and the glucose and fructose present in tobacco. These reducing sugars are in equilibrium (in solution) between the cyclic and acyclic form, and oxygen exchange can take place even under neutral conditions. The quantitative determination of the reducing sugars present in the Bright tobacco used as well as the extent of ${ }^{18} \mathrm{O}$-enrichment is presented in Table 7. A quantitative determination of the two reducing sugars showed the expected levels. Equilibrating with $\mathrm{H}_{2}{ }^{18} \mathrm{O}$ for 48 hours and oven treating the tobacco resulted in a decrease of glucose and fructose content indicating that a decomposition of the reducing sugars had taken place. Furthermore, oxygen-18 incorporation was found in $55 \%$ of the glucose and $74 \%$ of the fructose. Subjecting this same tobacco to an additional $\mathrm{H}_{2}{ }^{18} \mathrm{O}$ - $\mathrm{OV}$ treatment further reduced the levels of glucose and fructose while the levels of oxygen incorporation remained constant. The data are consistent with and support the results observed in the acetic acid experiments; both glucose and fructose readily incorporate oxygen-18 during the equilibration procedure. In an attempt to account for the total amount of $\mathrm{H}_{2}{ }^{18} \mathrm{O}$ lost during the equilibration step due to the exchange mechanism, it was calculated that approximately $50 \%$ of the total unaccounted $\mathrm{H}_{2}{ }^{18} \mathrm{O}$ can be attributed to oxygen18 incorporation in the reducing sugars. The remainder of the unaccounted oxygen-18 can certainly involve incorporation in other oxygen-containing organic compounds including, for example, alcohols, higher molecular weight acids, and saccharides.

\section{SUMMARY}

An investigation into the standard oven volatile procedure has been completed. Results have been presented which support the conclusion that $\approx 0.5 \%$ (tobacco dry weight basis) of the oven volatiles are generated via decomposition of tobacco constituents. The use of oxygen-18 labelled water for equilibrating tobacco has provided the probe necessary to differentiate between equilibrium moisture and water generated during the oven volatile test. Mass spectrometry was utilized to detect isotopically labelled tobacco constituents. Observations that $34 \%$ of the acetic acid and a significant portion $(>50 \%)$ of the reducing sugars exhibit oxygen-18 incorporation indicate the dynamic and interactive nature of the tobacco/ water system.

\section{ZUSAMMENFASSUNG}

Die Standard-Trockenschrankmethode zur Bestimmung flüchtiger Substanzen wurde eingehend untersucht. Aus den dargelegten experimentellen Befunden wird geschlossen, daß - bezogen auf die Trodkensubstanz - ungefähr $0,5 \%$ der erhaltenen flüchtigen Substanzen auf die Zersetzung von Tabakinhaltsstoffen zurüdkzuführen ist. $\mathrm{Da}$ durch, daß der Tabak unter Einsatz von mit ${ }^{18}$ Sauerstoff markiertem Wasser zum hygroskopischen Gleichgewicht gebracht wurde, war es möglich, zwischen der Gleichgewichtsfeuchte und dem Wasser $\mathrm{zu}$ unterscheiden, das sich während der thermischen Erhitzung bildet. Mittels Massenspektrometrie wurden die isotopenmarkierten Komponenten des Tabaks nachgewiesen. Es zeigte sich, daß ${ }^{18}$ Sauerstoff von $34 \%$ der Essigsäure und einem erheblichen Teil $(>50 \%)$ der reduzierenden Zudker aufgenommen wird, wodurch der dynamische Charakter und die Wechselwirkungen innerhalb des Tabak/Wasser-Systems sichtbar werden. 
Une étude approfondie de la methode standard pour la détermination des substances volatiles par le séchage au four a été effectuée. Les résultats permettent de conclure que, par rapport au poids du tabac sec, $0,5 \%$ environ des substances volatiles sont produites par la décomposition de constituants du tabac. L'utilisation d'eau marquée à l'oxygène ${ }^{18}$ pour équilibrer le tabac a permis de différencier l'humidité d'équilibre et l'eau produite chimiquement pendant le séchage au four. Des constituants du tabac marqués à l'aide d'isotopes ont été identifiés par la spectrométrie de masse. Le fait que $34 \%$ de l'acide acétique et une quantité importante $(>50 \%)$ des sucres réducteurs contiennent de l'oxygène ${ }^{18}$ démontre le caractère dynamique et interactif du système tabac/eau.

\section{REFERENCES}

1. Samfield, M.: The moisture content of tobacco, Part III: The effect of moisture on the processing of tobacco for cigarette manufacturing; Tobacco Int.176, No. 5, 1974, p. 44-46.

2. Samfield, M.: The moisture content of tobacco, Part III; Tobacco Int. 176, No. 8, 1974, p. 22-24.

3. Samfield, M.: The drying of tobacco, Part II: theory; Tobacco Int. 176, No. 19, 1974, p. 50, 52 and 54.

4. For a general review of methods for the determination of water see:

Mitchell, J.: Methods for the determination of water in polymers; Anal. Chem. Acta 81 (1976) 231.

McClure, W. F.: Evaluation of methods and instruments for measuring the moisture content of tobacco; Proceedings of the Coresta/26th Tobacco Chemists' Research Joint Conference held in Williamsburg, Va., U.S.A., in October 1972, p. 140.

5. Official Methods of Analysis of the Association of Official Analytical Chemists, Washington, D.C., 12th ed., 52 (1975).

6. Gold, V.: Protolytic processes in $\mathrm{H}_{2} \mathrm{O}-\mathrm{D}_{2} \mathrm{O}$ mixtures; Adv. Phys. Org. Chem. 7 (1969) 259.

7. Evano, B., K. M. Smith, G. N. LaMar and D. B.
Viscio: Regioselective base-catalyzed exchange of ring methyl protons in protoporphyrin, IX. A new facet of porphyrin chemistry; J. Am. chem. Soc. 99 (1976) 7070 .

8. Bell, R. P.: Recent advances in the study of kinetic hydrogen isotope effects; Chem. Soc. Rev. 3 (1974) 513.

9. Samuel, D., and B. L. Silver: Oxygen isotope exchange reactions of organic compounds; Adv. Phys. Org. Chem. 3 (1965) 123.

10. Betts, R. H., J. Bron, W. D. Buchannon and D. K. Y. Wu: Oxygen-18 isotope effects in the liquid water-pyridine system as a probe of intermolecular forces; Can. J. Chem. 55 (1977) 2966.

11. Samuel, D., and I. Wassermann: A new method for the synthesis of $18 \mathrm{O}$-labelled potassium nitrite and related compounds; J. Label. Compounds 7 (1971) 355.

12. Pryor, W. A., and V. Tonellato: Nucleophilic displacements at sulfur, III. The exchange of oxygen18 between sodium thiosulfate-18O and water; $J$. Amer. Chem. Soc. 89 (1967) 3379.

13. Lang, A. R. G., and S. G. Mason: The exchange of oxygen 18 between cellulose, adsorbed water, and water vapor; Can. J. Chem. 37 (1959) 1829.

14. Bell, R. P.: The reversible hydration of carbonyl compounds; Adv. Phys. Org. Chem. 4 (1966) 1.

\section{Adknowledgements}

The assistance of Cynthia Bright for ber contribution to this manuscript is adknowledged. Her work on the Karl Fisdher determination of water in tobacco was valuable in the course of the present study. We further recognize the assistance of $W$. Ryan for thermogravimetric analysis data, J. Bivins for the special glassware, C. Kroustalis for the sugar and acid determinations by gas dromatography, and $F$. Hatd for his excellent gas dromatography - mass spectrometry work on determining percent ${ }^{18} \mathrm{O}$ incorporation in acetic acid and the reducing sugars.

Authors' address:

Philip Morris U.S.A., Research Center, P.O. Box 26583, Ricbmond, Virginia, 23261, U.S.A. 